\title{
YYPO-PSO Algorithm Based Power Quality Control in a Grid-Connected Hybrid System
}

\author{
Dipanjan Dey Sarkar ${ }^{1}$, Dr. Charanjiv Gupta ${ }^{2}$ \\ ${ }^{1}$ SLIET, India, dipanjansarkar10@gmail.com \\ ${ }^{2}$ SLIET, India, guptacharanjiv@yahoo.com
}

\begin{abstract}
Micro-grid is a potential solution for the integration and management of renewable energy generation. Power generation through renewable energy sources has become more preferential and cost-effective, by articulating small scale distributed energy resources, micro-grids are becoming an alternative method in electrical power generation at the distribution voltage level. The increment of nonlinear loads and power electronic interfaced distribution generation system (DG) in the grid creates power quality issues like harmonic distortions in the distributed power system [6] [18]. The microgrid proposed in this paper consists of a photovoltaic array which represents the main generation unit and a three-phase induction generator that supplements the variable power generated by the photovoltaic array; a battery bank is included in the micro-grid to reduce the burden of the power generated by the micro-grid during the peak period [19] [20]. The power electronic interface maintains the necessary adaptability, security and reliability of operation between renewable sources and the distribution system [18]. In this paper, a comprehensive survey on micro-grid to improve the power quality parameters like THD is taken as the main objective with the help of suitable hybrid optimization algorithm, harmonic filters, controllers and battery storage.
\end{abstract}

Key words:Micro-grid, Renewable Resources, Power Quality Control, YYPO, PSO, VSI, MPPT, THD.

\section{INTRODUCTION}

A "micro-grid" is a group of interconnected and flexible loads, comprising Low-Voltage (LV) distribution systems with Distributed Energy Resources (DERs) within clearly defined electrical boundaries that act as a single controllable entity with respect to the grid. The advanced micro-grid controllers have expedited connection of micro-grids to the main grid and have led to an increase in a multitude of applications of grid-tied micro grids [16]. This research paper deals with certain issues faced in the field of hybrid power generation systems and power quality control microgrids.The major difficulty of a micro grid operation is the controlling ofvoltage and frequency with power requirement deviation [12]. Thus, structuring of VSI controller is important to manage the parameters under load variation [17] [20]. Formerly, different conventional control strategies have been used for increasing the reliability the renewable energy sources [9] . PI method [5], PR method
[5], Hysteresis control method [5], Particle Swarm Optimization (PSO) and Artificial Bee Colony (ABC)algorithm etc. have been used be forehand for reliability and performance enhancement for the shortcomings of conventional methods. However, these control algorithms are very complex in nature, and there is a need for an efficient and relatively easier heuristic control algorithm [20]. Hence, in this paper, the YingYang Pair Optimisation (YYPO) along with Particle Swarm Optimisation (PSO) is used for power quality optimisation. The main research objectives using the YYPO-PSO method are1. Analysis of a hybrid-style microgrid for non-linear loads. 2.Modelling and simulation of the hybrid system for specific cases with available REN resources.

\section{POWER QUALITY CONTROL ISSUESIN MICRO- GRID}

"Power Quality" refers to the electrical system's ability to create a perfect power supply that has a pure noise-free sinusoidal waveform, and is always stable considering voltage and frequency [6]. In practical situations, non-linear loads regularly impose disturbances on the grid that make significant deviations from ideal output characteristics [13]. Although micro-grids are traditionally designed to be energy selfsufficient, their infrequent availability and unexpected output variations cause unexpected power shortage or excessive generation. These result in unacceptable voltage or frequency deviation in the micro-grids. To remedy such situations, such micro-grids are temporarily interconnected to a suitable neighboring micro-grid to exchange power and improve the voltage and frequency deviations and power quality issues. The most important power quality issue is voltage stability [6]. Voltage regulation is mainly affected by the reactive power imbalance and the excitation system time constant[12].

\section{DESIGNOF MICRO-GRID}

A modern MG will include renewable and fossil fuel generation, energy storage facilities and load control.

\subsection{Local generation unit}

A micro-grid presents various types of renewable resources that provide electric power. These resources are branched into two major groups - Renewable thermal energy resources (e.g. 
biogas generators, biodiesel generators) and renewable generation resources (e.g. solar cells).

\subsection{Energy Storage}

Energy storage is able to perform multiple functions like ensuring power quality, frequency and voltage regulation, smoothing the power output, providing backup power for the system and playing important role in cost optimization [1][15][19].

\subsection{Point of common coupling (PCC)}

PCC is the point in the electric circuit where a micro-grid is connected to the main grid [16].

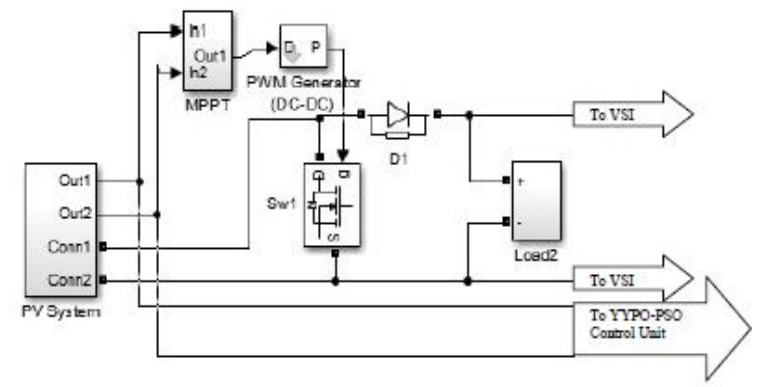

Fig.1: PV Module with MPPT and MOSFET Converter

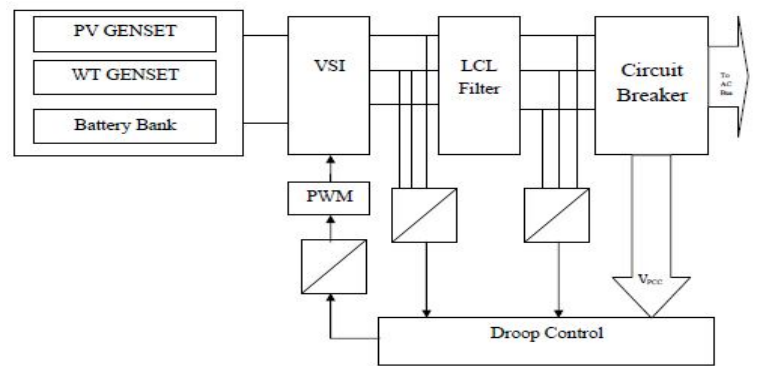

Fig. 2: AC Grid-Connected Inverter Control Diagram

The proposed system contains a grid side inverter that is used to deliver power at constant voltage. Output power is regulated through the in-phase current component that is proportional to the load demand. The proposed control mechanism for grid connected inverter in which droop controller allows delivery of power output by generating an error signal from measured and command signals[10] [11]. The PCC power quality can be improved by effective design of controller and LCL filter[14] [20]. Pulse Width Modulation (PWM) techniques are utilised for constant amplitude pulses to the PMOSFET inverter. The pulse widths are modulated to obtain desired inverter output voltage with reduced third and fifth order harmonic contents[20]. Lower order harmonics are reduced using high number of pulses. Monitoring and analysis systems are widely used for power quality control [6]. The MG control model is analyzed for AC voltage and battery and inverter currents. The voltage source inverter delivers the output current and load voltage to droop controlled MG. Grid voltage and current are measured and active and reactive powers are calculated [9][10][11].

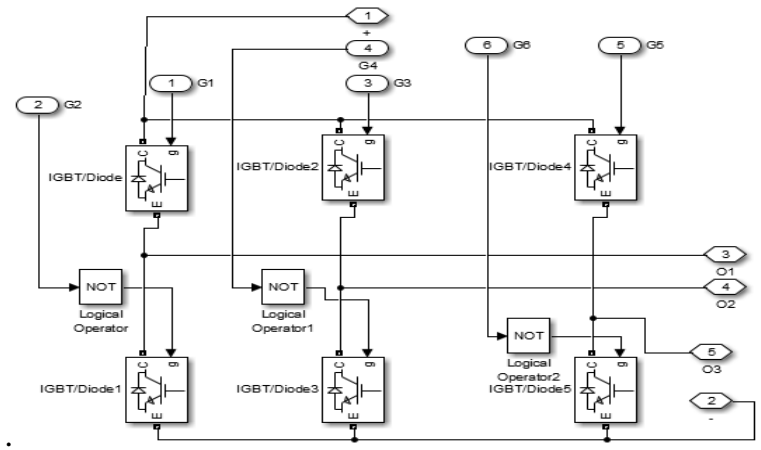

Fig. 3: VSI Diagram with IGBT Modules used within Simulation

\section{POWER QUALITY CONTROLSTRATEGY}

In this paper, YYPO with PSO is used to handle the loadsharing problem. The droop control unit consists of a unit of YYPO and PSO for optimization and inverter control. The VSI gate pulses are obtained from the YYPO and PSO algorithm unit, and it is given to the solar PV inverter and battery inverter and the corresponding output is obtained. For maximum power point tracking (MPPT), the voltage and currents of PV array are used as references and charging or discharging current of battery are calculated by the converter for MPPT.

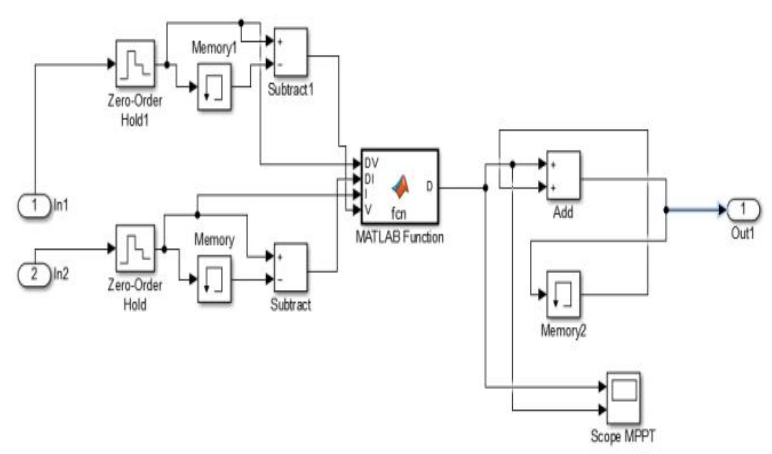

Fig.4: MPPT Setup in Proposed MG Model

YYPO optimization process is one of the latest metaheuristic algorithms influenced by the knowledge of balance between many discordant ideas. This optimizer employs two random points $\left(\mathrm{p}_{1}\right.$ and $\left.\mathrm{p}_{2}\right)$ to search the problem hyperspace. The points $\mathrm{p}_{1}$ and $\mathrm{p}_{2}$ are generated in the initial step of YYPO algorithm inside the domain of $(0,1)$ and their fitness are assessed [2] [3]. The point with better fitness is denoted as $\mathrm{p}_{1}$ and the other one is denoted as $\mathrm{p}_{2}$. The required parameters in terms of the minimum and maximum number of archival updates $\left(\mathrm{I}_{\min }\right.$ and $\left.I_{\max }\right)$ and the expansion/contraction factor $(\alpha)$ need to be specified [2][3]. The number of archive updates is randomly generated between $I_{\min }$ and $I_{\max }$ [2][3].As a consequence, the iteration loop is initiated and the fitness of the two points is compared. If $\mathrm{p}_{2}$ is fitter than $\mathrm{p}_{1}$, then the points and their corresponding ' $r$ ' values are interchanged, which ensures that the iteration starts with the fitter point as $p_{1}[2][3]$. The point $p_{1}$ assumes its role in exploitation phase, while it tries to highlight the exploration behaviors [2][3]. The points $\mathrm{p}_{1}$ and $\mathrm{p}_{2}$ act as overseer nodes to help in the hyper sphere measurements inside the solution space indicated by radii of $r_{1}$ and $r_{2}$, respectively 
[2][3]. These spans have a self-adaptive nature such that $r_{1}$ has a tendency to every so often decrease and $r_{2}$ to rise [2][3]. The YYPO involves two main phases of operation:

\subsection{Splitting phase}

The involvements to the splitting phase are one of the points ( $\mathrm{p}_{1}$ or $\mathrm{p}_{2}$ ) along with its radii $\left(\mathrm{r}_{1}\right.$ and $\left.\mathrm{r}_{2}\right)$. Although both points undergo the splitting stage, only a single point (described as p) along with its radii (r) undergoes the splitting stage at a time. The splitting stage is planned in order to produce new points in the hyper sphere (around the point $\mathrm{p}$ with the radius $\mathrm{r}$ ) at directions as different as possible, while keeping up a level of randomness [2]. The new points can be scattered using two procedures with equal probability:

\section{i. One-way Splitting}

In One-way splitting, 2D copies of the point $\mathrm{p}$ are kept as then; one variable of each in matrix $[\mathrm{Y}]$ is balanced by the following equations, which can be considered as a matrix of size (2DxD).

$Y_{j}^{j}=Y^{j}+a * r$
$Y_{D+j}^{j}=Y^{j}-a * r \quad j=1,2,3, \ldots \ldots, D$
$j=1,2,3, \ldots \ldots, D$

\section{ii. D-way Splitting}

Here, the binary matrix $[M]$ is built by '2D' random binary strings of length ' $\mathrm{D}$ ' comprised of distinctive integers between ' 0 ' and '2D-1'. While a means a random number between zero and one. In the D-way method, all variables of each point 'p' are updated.

$$
\begin{aligned}
& \mathrm{Y}_{\mathrm{k}}^{\mathrm{j}}=\mathrm{Y}^{\mathrm{j}}+\mathrm{a} *\left(\frac{r}{\sqrt{2}}\right) \\
& \mathrm{Y}_{\mathrm{k}}^{\mathrm{j}}=\mathrm{Y}^{\mathrm{j}}+\mathrm{a} *\left(\frac{r}{\sqrt{2}}\right) \text { else }
\end{aligned}
$$

\subsection{Archival phase}

The archive phase is initiated after the required number of archive updates has been reached and it is to be noted that the archive contains '2I' points at this stage, corresponding to the two points $\left(\mathrm{p}_{1}\right.$ or $\left.\mathrm{p}_{2}\right)$ being added at each update before the splitting stage [2] [3].

$$
\begin{gathered}
\mathrm{r}_{1}=\mathrm{r}_{1}-\left(\mathrm{r}_{1} / \alpha\right) \\
\mathrm{r}_{2}=\mathrm{r}_{2}-\left(\mathrm{r}_{2} / \alpha\right)(5)
\end{gathered}
$$

At the end of the archive stage, the archive matrix is set to null, and a new value for the number of archive updates $I$ is randomly generated within its specified bounds $I_{\min }$ andI $I_{\max }$ [2] [3].

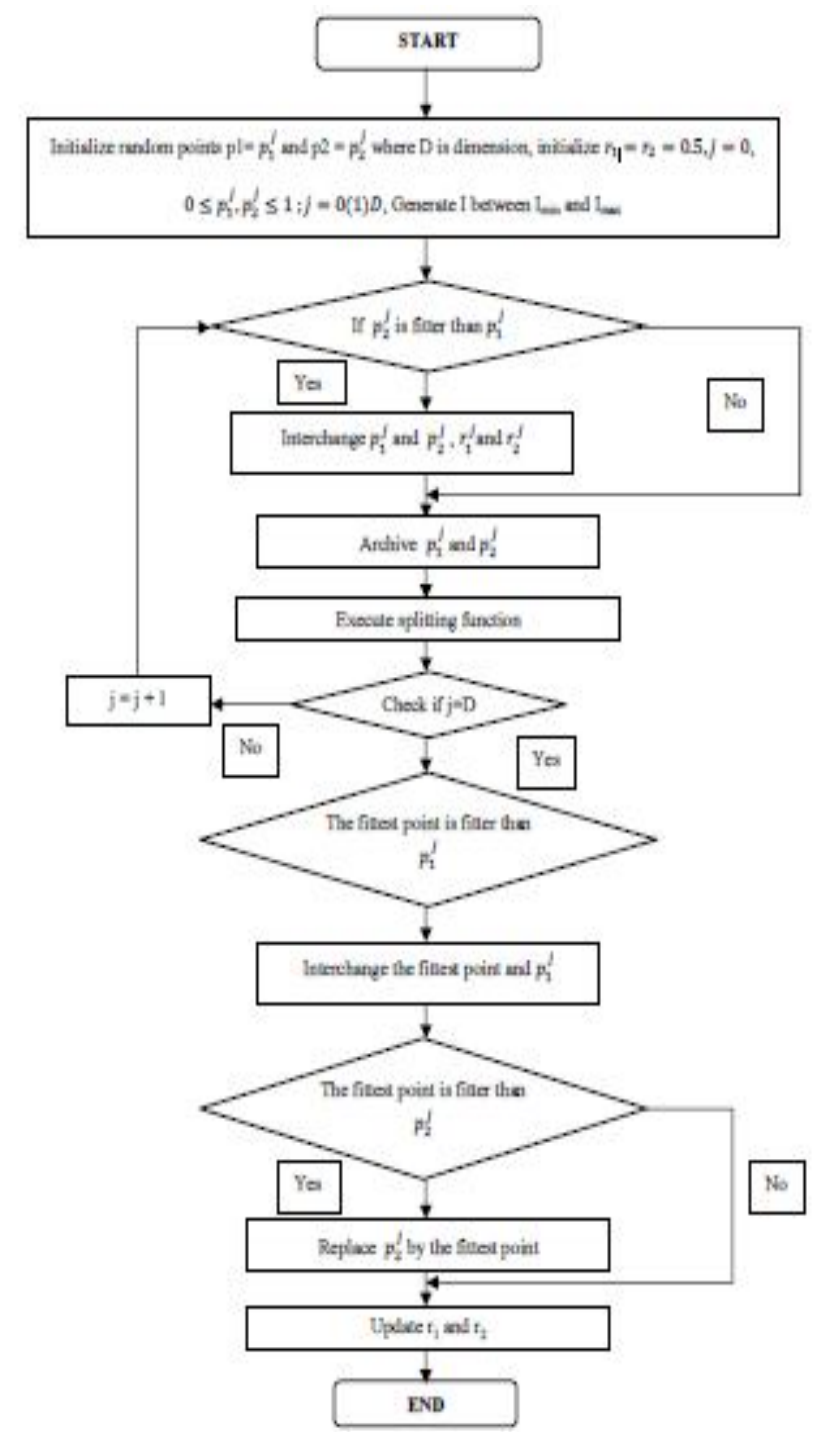

Fig.5: YYPO Algorithm Flowchart

The PSO system is initialized with a population of random solutions and searches for optima by updating generations [4]. In PSO, the potential solutions, called 'particles' fly through the problem space by following the current optimum particles [4].All particles have fitness values, that are evaluated by the fitness function to be optimized, and have velocities, which direct the flying of the particles[4]. In every iteration, each particle is updated by following two "best" values[4]. The first one is the best solution (fitness) it has achieved so far. The fitness value is also archived[4]. This value is called $\mathrm{P}_{\text {best }}$. Another "best" value that is tracked by the particle swarm optimizer is the best value obtained so far by any particle in the population[4]. This best value is called Global Best $\left(\mathrm{G}_{\text {best }}\right)$. When a particle takes part of the population as its topological neighbors, the best value is a Local Best and is called $\mathrm{L}_{\text {best }}$. After finding the two best values, the particle updates its velocity and positions[4]. The inclusion of random variables endows the PSO with the ability of stochastic searching [4]. 


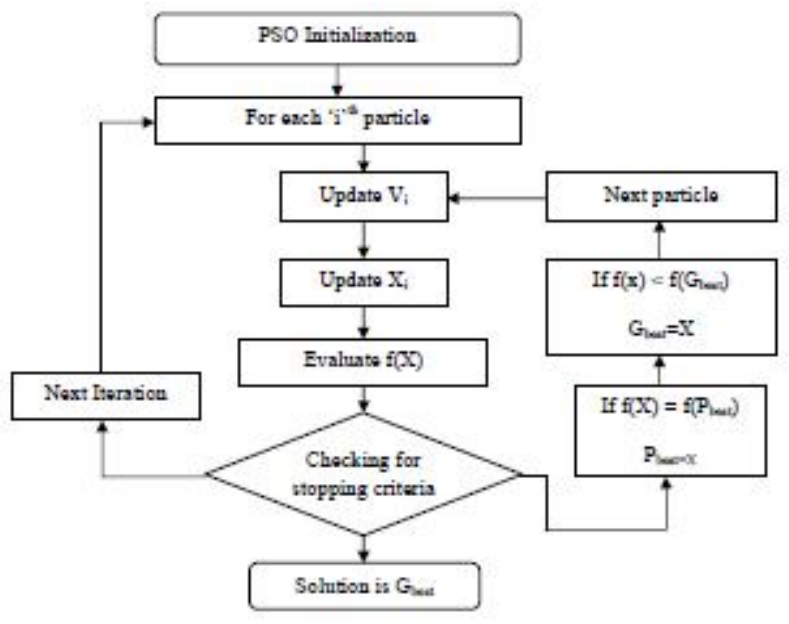

Fig.6: PSO Algorithm Flowchart

After each updates, value of $\mathrm{V}_{\mathrm{i}}$ should be checked and secured within a pre-specified range to avoid extreme random changes. Particle velocities on each dimension must be restricted to a maximum velocity $\mathrm{V}_{\text {max }}$. If the sum of accelerations causes the velocity on that dimension to exceed $\mathrm{V}_{\max }$, which is prespecified by the user, and then the velocity on that dimension is limited to $\mathrm{V}_{\max }[4]$.

The velocity and position equations are:

$\mathrm{V}_{\mathrm{i}}^{\mathrm{t}+1}=\omega^{*} \mathrm{~V}_{\mathrm{i}}^{\mathrm{t}}+\mathrm{c}_{\mathrm{i}}^{*} \varphi_{1}\left(\mathrm{p}_{\mathrm{i}}-\mathrm{X}_{\mathrm{i}}^{\mathrm{t}}\right)+\mathrm{c}_{2} * \varphi_{2}\left(\mathrm{p}_{\mathrm{g}}-\mathrm{X}_{\mathrm{i}}^{\mathrm{t}}\right)$

$$
\begin{aligned}
X_{i}^{t+1}= & X_{i}^{t}+V_{i}^{t+1}(7) \\
& x=2 /\left|2-\varphi-\sqrt{ }\left(\varphi^{2}-4 \varphi\right)\right| \varphi=c_{1}+c_{2}, \varphi>4
\end{aligned}
$$

The YYPO optimizer is utilized as an extra step inside the PSO algorithm. The main structure of combined YYPO-PSO algorithm is similar to the basic PSO. In YYPO-PSO algorithm, the YYPO operators have a constructive effect on the precision of solutions based on the two best agents in the sorted population [2] [3] [4].

\section{RESULTSAND DISCUSSION}

Different loads are connected with the $\mathrm{MG}$; one is pure resistive and another inductive type. The following readings and circuit characteristic profiles are obtained from MATLAB/SIMULINK simulation of the MG system designed.

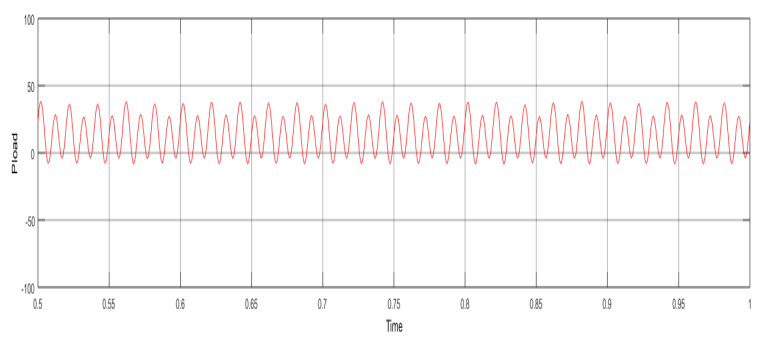

Fig. 7: Active Power Profile of Load

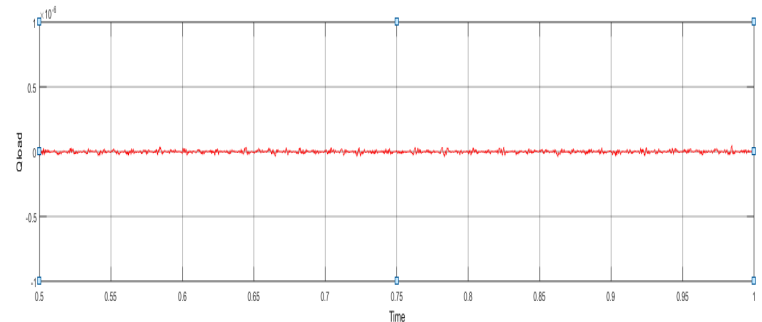

Fig. 8: Reactive Power Profile of Load

The following graphs are obtained for load side total harmonic distortion (THD) for fundamental frequency component, $3^{\text {rd }}$ harmonics and $5^{\text {th }}$ harmonics respectively.
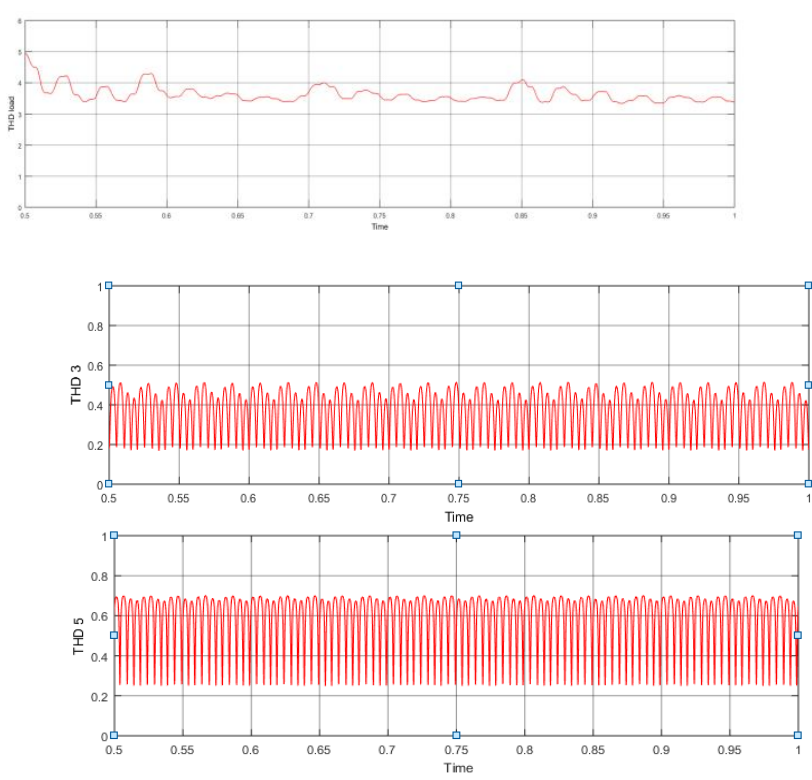

Fig. 9: Load Side THD Profiles

The following graphs are obtained for PV side total harmonic distortion (THD) for fundamental frequency component, $3^{\text {rd }}$ harmonics and $5^{\text {th }}$ harmonics respectively.
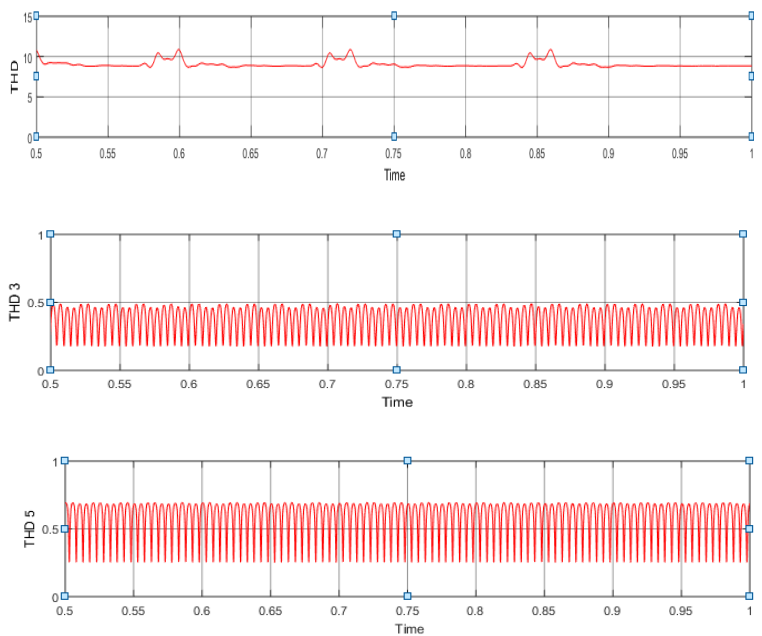

Fig. 10: PV Side THD Profiles 
The following graphs are obtained for load side voltage and current profiles.

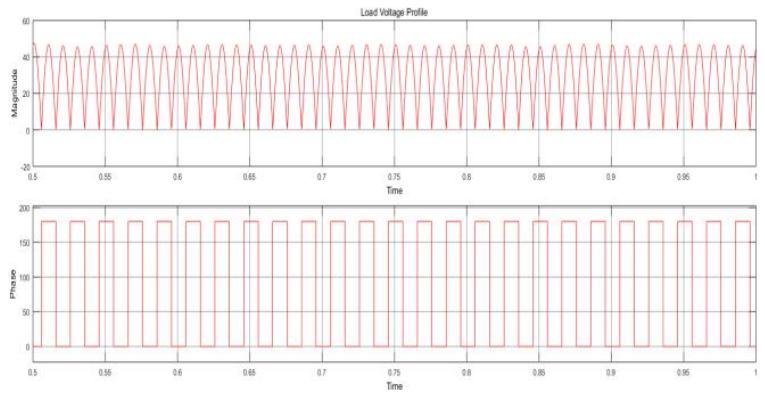

Fig. 11: Load Side Voltage Profile

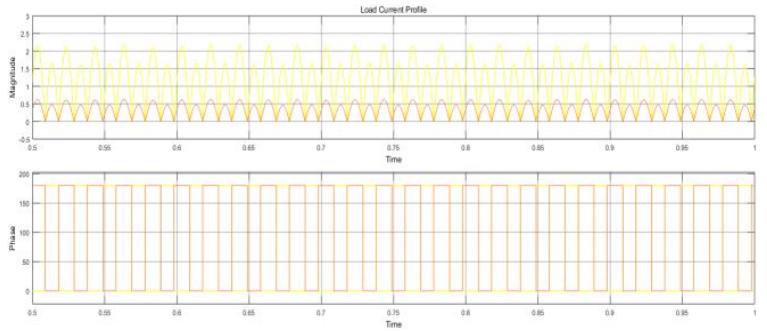

Fig. 12: Load Side Current Profile

The following graphs are obtained for PV side active and reactive power profiles.
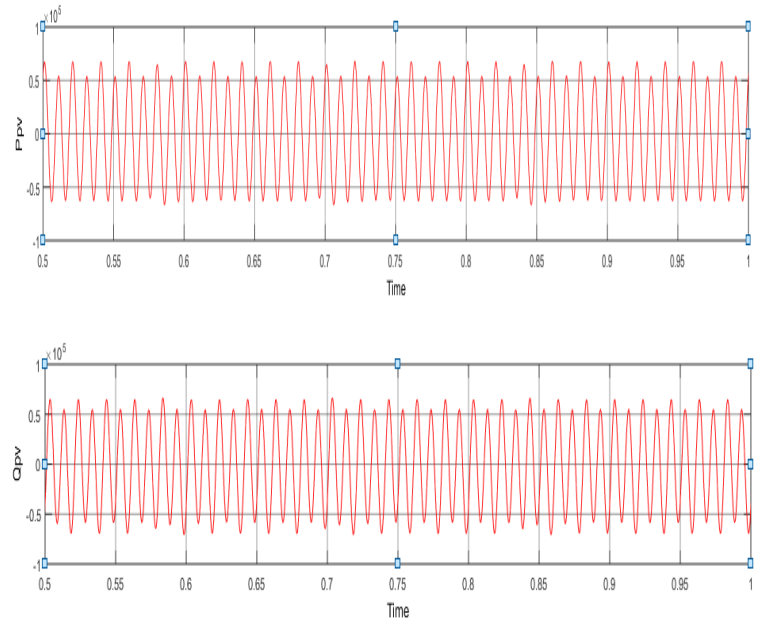

Fig. 13: PV GENSET Active and Reactive Power Profiles

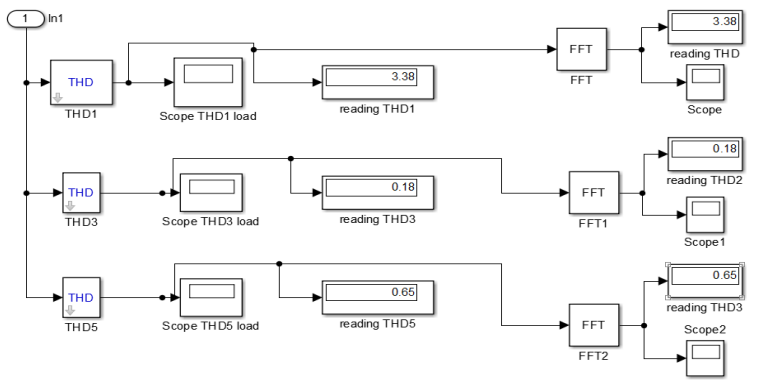

Fig. 14: Load Side THD Readings
Total Harmonic Distortion (THD) in the output power gives us an idea about the extent the harmonics distorts the output. Lower values of (THD) favors higher power quality[20]. The use of YYPO-PSO method with improved tracking responses decreases THD by eliminating much of the higher harmonics[20].

\begin{tabular}{|c|c|}
\hline PV side & THD (\%) \\
\hline Fundamental Frequency & 8.83 \\
$3^{\text {rd }}$ Harmonics & 0.34 \\
$5^{\text {th }}$ Harmonics & 0.69 \\
\hline Load side & THD (\%) \\
\hline Fundamental Frequency & 3.38 \\
$3^{\text {rd }}$ Harmonics & 0.18 \\
$5^{\text {th }}$ Harmonics & 0.65 \\
\hline
\end{tabular}

Table 1: THD Values for Harmonics

Among advantages and disadvantages of many existing control methods, PI controller is simple in design. It provides satisfactory performance in a balanced load, but it fails to reach optimal performance when applied to unbalanced system for harmonic compensation and offers a THD of $16.02 \%$.PI controllers have slower response time for V.R. and smoothing out voltage fluctuations. PR controllers ensure elimination of harmonics and zero steady state error with excellent reference tracking but only near controller resonant frequency. It offers a THD of $16.71 \%$. Hysteresis Current $(\mathrm{H} \square)$ controller has simple design and provides fast transient response but it does not have fixed switching frequency. It offers a THD of $16.54 \%$ [5].Comparing this with different controllers such as PI controller, PR controller and hysteresis current controller [5],the THD for fundamental frequency as follows:

\begin{tabular}{|c|c|}
\hline Method Name & $\begin{array}{r}\text { THD(\%) for Fundamental } \\
\text { Frequency }\end{array}$ \\
\hline PI controller & 16.02 \\
PR controller & 16.71 \\
H $_{\square}$ Controller & 16.54 \\
\hline System THD \\
(Load Side)
\end{tabular}

Table 2: THD Comparison for OtherControllers

\section{CONCLUSION}

The design and analysis of a 3-phase grid connected hybrid system using a hybrid YYPO-PSO algorithm offers an improved control over the MG than the existing PSO and other past algorithms. It is seen that the proposed YYPO-PSO algorithm provides a better control over power quality of MG. Comparing to other existing algorithms and controller methods [8]; YYPO-PSO provides better THD control [20], active and reactive power control and output voltage and output current control. Feasibility analysis of a hybrid power plant along with 
a bio-fuel GENSET with backups may be planned which can be carried out using MATLAB/SIMULINK software. Other software such as HOMER or Open DSScan be used for predictive analysis of load and cost estimation purposes [7].

\section{REFERENCES}

[1] M. Guarnieri,A. Bovo,A. Giovannelli, P. Mattavelli (2018). "The VERITAS Multi-technology micro grid experiment: A design review". IEEE Industrial Electronics Magazine. 12 (3): 19 31.doi:10.1109/MIE.2018.2855735

[2] Bo Yang, Tao Yu, H. Shu, D. Zhu, F. Zeng, Y. Sang, Lin Jiang, "Perturbation Observer Based FractionalOrder PID Control of Photovoltaic Inverters for Solar Energy Harvesting via Yin-Yang-pair Optimization". Energy Conversion and Management 171 (2018) 170-187.

[3] V.Punnathanam, P.Kotecha, "Yin-Yang-pair Optimization: A novel lightweight optimization Algorithm", Science Direct (2016), Engineering Applications of Artificial Intelligence 54(2016)62-79.

[4] J. F. Schutte, The Particle Swarm Optimization Algorithm. EGM 6365- Structural Optimization, 2005.

[5] V. Lavanya, N. S. Kumar, "A Review of Control Strategies for Power Quality Improvement in Micro grid". IJRER, March 2018.

[6] E. Hossain, M. Tür, S. K.Padmanaban, Selim Ay, and Imtiaj Khan,"Analysis and Mitigation of Power Quality Issues in Distributed Generation Systems Using Custom Power Devices". IEEE 2018, doi: 10.1109/ACCESS.2018.2814981.

[7] A. Kumar, A. R. Singh, Y. Deng, X. He, P. Kumar and R. C. Bansal, "A novel methodological framework for the design of sustainable rural micro grid for developing nations". IEEE 2018,doi:10.1109/ ACCESS.2018.2832460.

[8] N. H. Kanan, P. Kanjiya, H. H. Zeineldin, W. Xiao, J. L. Kirtley and V. Khadkikar, "A Modified Control Topology for Improving Stability Margins in MG with Droop Controlled IBDG". Masdar Institute of Science and Technology, Abu Dhabi, UAE, MIT, Cambridge, USA.

[9] U. B. Tayab, M. A. Bin Roslan, L. J. Hwai, M. Kashif, "A Review of Droop Control Techniques for MicroGrid". ScienceDirect (2017) Renewable and Sustainable Energy Reviews 76 (2017) 717-727.

[10] L.J. Qin, W.T. Yang, "Micro-Grid Converter Droop Control Strategy and Simulation". ISBN: 978-161804-279-8.
[11] Estefania Planas, A. Gil-de-Muro, J. Andreu , I. Kortabarria, I. Martinez de Alegri, "General Aspects, Hierarchical Controls and Droop Methods in Microgrids". Science Direct (2012), Renewable and Sustainable Energy Reviews 17 (2013) 147-159.

[12] X. Z. Xia, F. H. Wei, "Impacts of P-F \& Q-V Droop Control on Microgrids Transient Stability", Science Direct (2011), Physics Procedia 24 (2012) 276282/1875-389 doi:10.1016/j.phpro.2012.02.041. 2012 International Conference on Applied Physics and Industrial Engineering.

[13] H. Dong, S. Yuan, Z. Han, X. Ding, S. Ma and X. Han, "A Comprehensive Strategy for Power Quality Improvement of Multi-inverter Based Microgrid with Mixed Loads", IEEE (2018),doi: 10.1109/ACCESS.2018.2826923.

[14] M. A. Abusara, S. M. Sharkh, J. M. Guerrero, "Improved Droop Control Strategy for GridConnected Inverters". ScienceDirect (2015), Sustainable Energy, Grids and Networks 1(2015) 1019.

[15] X. Chang, F. Chen, Y. Li, Y. Wang and C. Xu, "Improved Power Allocation Strategy of Hybrid Energy Storage System in Islanding DC MicroGrid". The 6th International Conference on Renewable Power Generation (RPG) 19-20 October 2017.

[16] W. Feng, K. Sun, Y. Guan, J. M. Guerrero, X. Xiao, "PCC Voltage Power Quality Restoring Strategy Based on Droop Controlled Grid Connecting Microgrid". The 6th International Conference on Renewable Power Generation, (2017).

[17] M.S. Mahmoud, S. A. Hussain, M. A. Abid, "Modeling and Control of Microgrid:An Overview". ScienceDirect (2014), Journal of the Franklin Institute 351(2014)2822-2859.

[18] F. Zhang, H. Zhao, and M. Hong, "Operation of Networked Microgrids in a Distribution System". CSEE Journal of Power and Energy Systems, Vol. 1, No. 4, December 2015. doi:10.17775/CSEEJPES.2015.00043.

[19] Gurupraanesh Raman, Gururaghav Raman, J.C. Hsien Peng, W. Xiao, "Bridging the Transition to DC Distribution-A Hybrid Microgrid for Residential Apartments".IEEE 2017, 978-1-5386-4950-3/17.

[20] N. Chitra, A. S. Kumar, P. Priyadharshini and K. Prabaakaran, "Survey on Micro grid-Power Quality Improvement Techniques". Anna University and SKP Engineering College, Tiruvannamalai. 